On the second day, questions of 'coding' of information-sources were discussed - the transformations of message representations from one form to another-and of the possibility of improving rates of flow of information in noisy channels. Profs. A. E. Laemmel and P. Elias (United States) considered the theoretical bases of encoding so as to reduce the probability of error in, respectively, low and high noise-levels. 'Their colleague, Dr. D. A. Huffman, then showed ways in which such encodings might be carried out automatically, in practice.

A related field of work was surveyed, in the afternoon, which included study of preferred ways of cataloguing, filing or classifying data in, for example, libraries-the theory of 'clerical operations'. Mr. R. A. Fairthorne (Great Britain) has worked in close association with Dr. Calvin N, Mooers, of the United States, and gave a most humorous exposition of what a layman might otherwise guess to be a dry subject.

Real-life, human, language was the topic on the third day, with accounts of some of the remarkable statistical facts about it. Prof. W. Fucks, of Aachen, disclosed statistical data relating to nine different languages, ancient and modern, Eastern and Western, showing that they have certain forms in common. Prof. Fucks is well known for his claims to establish the authenticity of certain controversial classical texts by the use of statistical discriminating-functions applied to the words. Prof. A. S. C. Ross and Dr. D. A. Bell, of Birmingham, continued their earlier work (reported in the 1952 Symposium) of computing the degree of redundancy in a written language ; this time they chose written Welsh, because it is essentially a phonetic writing, and so their results bear at least some reasonable approximation to a spoken language (statistical data about spoken languages being extremely difficult to gather). Dr. B. Mandelbrot (Geneva and Grenoble) continued the discussion to the statistical laws which relate to languages. There are close relations between statistical laws of language and other biological laws, in particular those first exposed by J. C. Willis. The reasons for the similarity aro by no means clear, but the suggestion was offered, by Dr. Margaret Meade, that it arises from the fact that the various descriptive categories (phonemes, say, in language, and species or genera in biology) are set up by groups of people, in society. The laws may not be so much properties of 'nature', but of ourselves who set up descriptions and classifications.

The afternoon of this same day was devoted to "Mechanical Translation", the principal contributors being Drs. A. D. Booth and J. Cleave, of Birkbeck College, London, Prof. V. H. Yngve, of the Massachusetts Institute of Technology, and Profs. S. Ceccato and E. Maretti, from Italy. Distinction between translation and transeription (or encoding) was quickly drawn, and discussion largely concentrated upon the parts played by the syntactic and semantic rules in trans. lation. The machines, as at present constructed, operate necessarily upon syntactic rules, and it is indeed surprising the extent to which successful conversions of a text from one language to another may be accomplished, even on a word-by-word conversion basis. The speakers emphasized the practical achievements of their work, with examples of translation of scientific texts. The semantic rules may come in with the pre-and post-editing processes, using reasonably intelligent human beings. As might be expected, it is scientific texts which offer most promise, being to a large extent inter-cultural. The two Italian speakers gave a brief account of the approach of their operational school to problems of language and translation, leading to discussion of some of the philosophical difficulties and pitfalls.

During the afternoon, speakers from Britain, France and the United States outlined modern views upon the structure of physical speech signals, and upon aural and visual perception.

The final day was devoted to psychological and neurophysiological studies. 'Models' representing certain aspects of brain functioning were discussed which, in their main attributes, are nowadays far removed from the digital computer analogies which so plagued us a few years ago. The stress to-day is upon self-organizing models, in initial random connexion. A paper by W. K. Taylor (of University College, London) is likely to become a classic ; Taylor considers the properties essential to the elements of a mechanism which can 'learn by association', based upon known properties of neurons in living nerve cells and sense receptors-correct firing-rates, mutual interaction, facilitation and inhibition, accommodation-which determine the whole pattern of activity when associated. His analogue mechanisms are of the self-organizing type which, experimentally, exhibit primitive learning and adaptive behaviour.

Later in the same day, some varied uses of information theory were demonstrated in human behaviour studies, especially to give quantitative measures for experiments upon learning, motor skills, visual recognition and human operator capacity.

It was a happy sign of the times to hear, finally, a short report upon information theory developments in the U.S.S.R. from Prof. V. Siforov, the leader of the Russian delegation. He brought news of a number of well-known workers in the field, including the pioneers, Profs. A. Khinchin and A. Kolmogorov.

The Proceedings of this third London Symposium on Information Theory are to be published by Butterworths Scientific Publications, London. Colin Cherry

\section{CHOLESTEROL AND FAT METABOLISM}

A SYMPOSIUM on "Cholesterol and Fat Metabolism in Relation to Diet and Disease", arranged by the Scottish Group of the Nutrition Society jointly with the Biochemical Society, was held in Aberdeen on September 17. At an excellently attended meeting five papors were given as a basis of discussion, the speakers each making their characteristic contribution to the subject in hand. The subject-matter, covering the factors of diet and disease, proved attractive to biochemists, nutritionists and clinicians; and indeed the papers were so arranged that the more purely scientific aspects of the subject were followed by those parts of the problem of cholesterol and fat metabolism which are of more particular interest to pathologists and clinicians.

The subject, from the chemistry of the sterols to the treatment of atherosclerosis, is as full of interest as it is of difficulties, both in the investigation of the scientific problems and the interpretation of the complex of signs and symptoms which present them. selves to the clinician.

Dr. R. P. Cook, of the Department of Biochemistry, Queen's College, Dundee, opened with a paper on "Chemistry and Biochemistry of the Sterols with Special Reference to Cholesterol". After a brief but interesting reference to the historical development of 
our knowledge of cholesterol, he reviewed the structure of the sterols. He discussed fully the biological function of the sterols and concluded with an account of sterol absorption in various types of animals.

Dr. J. A. Lovern, of the Torry Research Station, Aberdeen, followed with a paper on "Methods of Investigating Cholesterol and Associated Lipids". The paper dealt with the general principles involved in the main sequence of operations in a study of the lipids of a tissue, with particular emphasis on cholesterol and its esters. In an excellent and highly technical account, he indicated the extraction difficulties associated with lipid protein complex formation and pointed out that they are not likely to be serious with cholesterol, and that a rigorous removal of non-lipid impurities is not essential if the investigation is concerned solely with cholesterol; but it was shown that separation problems are serious if the fatty acids of the cholesterol esters are to be examined. Detailed reference was made to the well-known drawbacks of the Liebermann-Burchard colorimetric method for cholesterol, these being associated with the transient nature of the colour and its sensitivity to experimental conditions. Such difficulties as arise, however, can be avoided by the use of alternative reactions. It was shown how metabolic studies with precursors labelled with deuterium and radioactive carbon have thrown much light on cholesterol synthesis and metabolism in the animal.

Of importance to those interested in the origins of the secretion of the adrenal glands were the remarks of Dr. G. S. Boyd, of the Department of Biochemistry, University of Edinburgh, when he spoke on "Some Aspects of Cholesterol Metabolism". Isotopic studies have shown how acetate must be involved in the total synthesis of the cholesterol molecule. He emphasized how true it is that while the adrenal cortex and the liver, particularly the latter, play an important part in the synthesis of this sterol, nevertheless other tissues such as the lungs, kidneys and spleen may in some species enter the field of biosynthesis. That the adult brain, rich in cholesterol, seems to be a non-participant in this biosynthesis does not indicate that the central nervous system has no part to play in the maze of activities which apparently have their origin in cholesterol or its precursors. It was apparent that we have only to think of the influence of the various steroids and steroid hormones on the hormonal activity of the anterior lobe of the pituitary gland, with its close links with the hypothalamic nuclei, to realize the complexities of the problem. A stimulated pituitary has a potent action in depleting cholesterol sources, especially in the adrenal cortex, and in forcing the production of cortical steroids and concurrently removing, from the circulating blood, cholesterol and especially cholesterol esters for the purpose of the restoration of depleted reserves. The complexities of the subject were further emphasized by Dr. Boyd in his remarks concerning liver glycogen and blood-sugar levels and the influence which they exert through the hypothalamus on the energy balance within the body.

The last two papers, given by Dr. I. Rannie, of the Department of Pathology, King's College, Newcastle upon Tyne, on "Experimental Cholesterol Atherosclerosis", and by Prof. H. W. Fullerton, Department of Medicine, University of Aberdeen, on "The Relationship of Lipæmia to Thrombosis and Atheroma", presented the problem of cholesterol and fat metabolism in its relation to disease. To the biochemist and the nutritionist, this aspect of the problem is apparently not without interest ; nevertheless, to the pathologist and more especially to the physician, with the care of the patient his supreme responsibility, it is of vital importance. In his references to experimental atherosclerosis Dr. Boyd, by a most illuminating series of slides, showed how lipid-bearing phagocytes or cholesterol taken up by reticuloendothelial cells may become imbedded in the wall of the artery and, in this connexion, referred to the important part played by the permeability of the vessel endothelium and how at sites of turbulent flow macromolecular substances can stick to and damage the endothelial lining of the vessel. It was further made abundantly clear that the problem is made the more difficult because of species differences, and that as a result of this, one has to be extremely careful in arriving at conclusions to note the type of animal from which results have been gleaned.

Prof. Fullerton, in discussing the more clinical aspects of the problem, gave it as his opinion that while a thrombosis or fibrin deposit is situated within the wall covered by $\in$ ndothelium, the initial abnormalities, at least in man, are to be found in the plasma and not in the wall of the artery. Prof. Fullerton corroborated the suggestion first put forward by Prof. Duguid that the factor responsible for intermittent fibrin formation is the ingestion of meals rich in fat. As a result of his own work, he showed that the amount of fat ingested at a meal may on many occasions exceed the critical level at which an increase in the coagulability of the blood occurs.

A matter which received a certain amount of attention was the relation of plasma cholesterol to the nature of the plasma lipoproteins, and the distribution of cholesterol between the $\alpha$ - and the larger $\beta$-lipoproteins. As a result of discussion, it became clear that an increase in plasma cholesterol, while it may lead to an accumulation in the plasma of abnormal lipoproteins of macro-molecular structure, does not provide an explanation of the processes upon which the development of the thrombic lesion within the arterial wall depends.

Sir Rudolph Peters, of the Institute of Animal Physiology, Babraham, Cambridge, took the chair during the first part of the meeting.

\section{YOUNG MANAGERS IN THE UNITED STATES}

$\mathrm{D}^{\mathrm{t}}$

URING the academic years 1951-52 and 195253 , funds were provided by the United States Government through the Mutual Security Agency for a study to be made of "the philosophy, principles and techniques of American business management" by a number of young managers from Britain. In each of the two years two groups travelled to the United States, attending the Universities of Cincinnati and Syracuse, respectively. Each course lasted for a period of nine months and the total number taking part in all the courses was sixty-three.

The young managers who carried out these studies are back at work in British industry. They have now published the outstanding impressions of the period that they spent in the United States, a summary of experience based not only upon courses of instruction but upon an overall total of 452 visits made to companies, trades unions, business associations and government departments ("Reporting Back". (Management Publications, Ltd.) 7s. 6d.). 